\title{
Accuracy of circulating microRNAs in diagnosis of sepsis: a systematic review and meta-analysis
}

Xiaomin Shen ${ }^{1}$, Jiajie Zhang ${ }^{2}$, Yicheng Huang ${ }^{2}$, Jiepeng Tong ${ }^{1}$, Li Zhang ${ }^{1}$, Zhijuan Zhang ${ }^{1}$, Wei Yu ${ }^{1 *}$ and Yunqing Qiu ${ }^{1 *}$

\begin{abstract}
Objectives: The aim of this study was to systematically assess the accuracy of circulating microRNAs (miRNAs) as a promising biomarker for sepsis via a meta-analysis.

Methods: PubMed, Cochrane Library, Embase, Web of Science, Scopus, and Ovid databases were searched up to April 3, 2020. The Quality in Prognostic Studies (QUADAS-2) tool was used to assess methodological quality. The pooled sensitivity (Sen), specificity (Spe), positive or negative likelihood ratios (PLR or NLR), diagnostic odds ratio (DOR), curve, and area under the curve (AUC) were calculated with 95\% confidence interval (95\% Cl). The overall accuracy $(\mathrm{OA})$ of miRNAs, procalcitonin (PCT), and C-reactive protein (CRP) was analyzed by the chi-square test.

Results: A total of 22 records were eligible for systematic review, including 2210 sepsis, 426 systemic inflammatory response syndrome (SIRS), and 1076 healthy controls (HC). The pooled Sen, Spe, and DOR of miRNAs were 0.80 (95\% Cl 0.75-0.83), 0.85 (95\% Cl 0.80-0.89), and 22 (15-32), respectively. The DOR of PCT and CRP were 17 (95\% Cl 4-68) and 7 (95\% Cl 1-48), respectively. The OA value of miRNAs (79.02\%) and PCT (76.95\%) were higher than CRP (61.22\%) $(P<0.000)$. The subgroup analysis indicated that miRNAs in adults, serum type, downregulation of miRNA expression, criteria of Sepsis-3, internal reference of non-U6, and dysregulation expression of miR-223 had superior diagnostic accuracy. In addition, there was no significant publication bias among the included studies. Fagan's nomogram showed valuable clinical utility.
\end{abstract}

Conclusions: Our meta-analysis indicated that the level of circulating miRNAs, particularly the miR-223, could be used as an indicator for sepsis.

Keywords: Sepsis, SIRS, miRNAs, Diagnosis, Biomarkers

\footnotetext{
* Correspondence: wyu@zju.edu.cn; qiuyq@zju.edu.cn

${ }^{1}$ State Key Laboratory for Diagnosis and Treatment of Infectious Diseases, National Clinical Research Center for Infectious Diseases, Collaborative Innovation Center for Diagnosis and Treatment of Infectious Diseases, Zhejiang Provincial Key Laboratory for Drug Clinical Research and Evaluation, The First Affiliated Hospital, Zhejiang University School of Medicine, Hangzhou, China

Full list of author information is available at the end of the article
}

(c) The Author(s). 2020 Open Access This article is licensed under a Creative Commons Attribution 4.0 International License, which permits use, sharing, adaptation, distribution and reproduction in any medium or format, as long as you give appropriate credit to the original author(s) and the source, provide a link to the Creative Commons licence, and indicate if changes were made. The images or other third party material in this article are included in the article's Creative Commons licence, unless indicated otherwise in a credit line to the material. If material is not included in the article's Creative Commons licence and your intended use is not permitted by statutory regulation or exceeds the permitted use, you will need to obtain permission directly from the copyright holder. To view a copy of this licence, visit http://creativecommons.org/licenses/by/4.0/ The Creative Commons Public Domain Dedication waiver (http://creativecommons.org/publicdomain/zero/1.0/) applies to the data made available in this article, unless otherwise stated in a credit line to the data. 


\section{Introduction}

Sepsis is defined as a life-threatening condition of organ dysfunction resulted from a dysregulated host response to infection [1]. Recent epidemiologic data have shown an increasing incidence of sepsis and septic shock with high mortality [2]. Although recent data suggested a declining trend in mortality, longer-term morbidity and decreased health-related quality of life remain a serious problem [3]. Additionally, the clinical syndrome of sepsis is difficult to diagnose. A previous study reported $50 \%$ of patients with sepsis were not correctly classified in the USA [4]. Early diagnosis of sepsis is crucial for improving the survival rate; however, traditional screening tools and biomarkers lack specificity [5].

MicroRNAs (miRNAs) are small non-coding RNAs, associated with the presence and severity of sepsis. Dysregulation of several miRNAs, such as miR-146a, miR-223, miR-15a, miR-16, and miR-150, was found in the peripheral blood of sepsis patients [6-9]. Previous studies have demonstrated the expression of miRNAs in sepsis had specific compartment characteristics, and serum-derived exosome miRNAs were considered to be a significant diagnosis marker and survival prediction factor [10]. In addition, miRNAs had shown to be involved in the regulation of the exacerbated inflammation, endothelial dysfunction, and coagulation cascade in sepsis [11]. miR-15a, miR-125b, and miR-146a have been shown to prevent NF- $\mathrm{kB}$ activation in sepsis by repressing TRAF6 and IRAK expression [10, 11]. However, the expression level of miRNAs showed differences in sepsis due to different population characteristics and normalization methodologies among different studies [11]. Therefore, a comprehensive and systematic metaanalysis of currently available data will facilitate the understanding of the diagnostic accuracy of these miRNAs in sepsis.

\section{Methods}

\section{Search strategy and selection criteria}

This meta-analysis was presented according to the Preferred Reporting Items for Systematic Reviews and Meta-Analyses statement (PRISMA) [12]. Six databases including PubMed, Cochrane Library, Embase, Web of Science, Scopus, and Ovid were searched by the end of April 3, 2020. The retrieval terms included "sepsis" or "Severe Sepsis" or "Pyemia" or "Septicemia" and "micro RNA" and "microRNAs" or "miRNA."

Literatures were considered eligible for inclusion using the following criteria: (1) the target population consisted of one or more circulating miRNAs for sepsis; (2) sufficient data to generate true positive (Tp), true negative $(\mathrm{Tn})$, false positive $(\mathrm{Fp})$, and false negative (Fn) directly or indirectly; and (3) either retrospective or prospective design studies. Studies that are excluded in our meta- analysis met the following criteria: (1) reviews, letters, correspondence, expert opinions, and editorial; (2) animal or in vitro studies; (3) duplicated information; and (4) insufficient information regarding the diagnosis value.

\section{Data collection}

Two investigators (XMS and WY) independently screened the records retrieved from the search after deduplication by title and abstract. Full-text studies that satisfied all the inclusion criteria were further screened for eligibility by the same investigators. Any discrepancies were resolved by a third reviewer (JJZ). Data extraction was performed by two review authors (JJZ and $\mathrm{YCH}$ ) independently, including author and year of publication, sample characteristics, diagnostic criteria, illness severity (APACHE II and SOFA score), and numbers of Tp, Tn, Fp, and Fn observations.

\section{Assessment of methodologic quality}

Quality Diagnostic Accuracy Studies-2 (QUADAS-2) was used to assess the methodological qualities of the included studies by independent authors (XMS and WY) [13]. Disagreements were resolved by a third reviewer (JPT).

\section{Data synthesis and statistical analysis}

The threshold effect was evaluated before data synthesis. The diagnostic index tests, including sensitivity (Sen), specificity (Spe), positive or negative likelihood ratios (PLR or NLR), diagnostic odds ratio (DOR), summary receiver operating characteristic (SROC), curve, and area under the curve (AUC), were quantified with 95\% confidence interval $(95 \% \mathrm{CI})$. Meta-analysis was performed using a bivariate random-effects model to estimate the summary diagnostic indexes. Heterogeneity was explored using meta-regression models, and subgroup analyses were further analyzed according to varied factors. Publication bias was evaluated by Deeks' funnel plot, and clinical utility was evaluated by Fagan's nomogram. STATA version 14 (STATA Corp, College Station, TX, USA) was used for all statistical analyses. The differences between the overall accuracy (OA), that is the proportion of $\mathrm{Tp}$ and $\mathrm{Tn}$ in all evaluated cases, of miRNAs, procalcitonin $(\mathrm{PCT})$, and $\mathrm{C}$-reactive protein (CRP) were analyzed by the chi-square test using SPSS Statistics 22 (IBM, China).

\section{Results}

Search results and methodological qualities of included studies

Our search yielded 2061 references through 6 electronic databases. After removing 1978 duplicates, animal or in vitro studies, irrelevant articles, and excluded article 
format, a total of 83 full-text references were screened for eligibility. Finally, 22 records were included in our systematic review [6-9, 14-31]. The detailed flow diagram of the study selection process is shown in Fig. 1.

The methodological qualities of the included articles were evaluated according to the QUADAS-2 criteria (Supplementary Figure 1). Risk of bias is mainly derived from the index test. The conduct or interpretation of the index test introduced high risk in 6 records $[7,8,17,19$, $23,28]$ and unclear risk in 13 articles [6, 14-16, 18, 20, 21, 25-27, 29-31].

\section{Characteristics of included studies}

A total of 2337 patients, including 14 studies of systemic inflammatory response syndrome (SIRS), 2 studies of local infections, and 14 studies of healthy controls (HC), provided data regarding the diagnostic accuracy of miRNAs. The characteristics of the included studies and patients are presented in Table 1 and Supplemental Table 1. Single miRNAs were reported in all studies. Among the 29 studies, 8 studies were about the expression of miRNAs in children, and 21 studies were about adults. In addition, there were 15 studies of serum specimens and 13 studies of plasma specimens.

\section{Threshold effect}

The Spearman correlation coefficient for miRNAs was $0.127(P=0.503)$ using a rank correlation test. The shape of the ROC plot was not arm and shoulder shape (Supplementary Figure 2a). These results indicated the heterogeneity among the included studies was not caused by the threshold effect [32].

\section{Diagnostic accuracy of miRNAs, procalcitonin, and C- reactive protein for sepsis}

The random-effects model was used to synthesize the data due to significant heterogeneity among the 30 studies $\left(I^{2}=86.49 \%\right.$ for Sen, $I^{2}=78.03 \%$ for Spe, $I^{2}=$ $100 \%$ for DOR). Outliers, falling outside 95\% CI, could be the main source of heterogeneity [Supplementary Figure 2b].

The pooled Sen and Spe were 0.80 (95\% CI 0.75-0.83) and 0.85 (95\% CI 0.80-0.89), respectively (Fig. 2). The PLR and NLR were 5.3 (95\% CI 4.0-6.9) and 0.24 (95\% CI $0.20-0.29)$, respectively. The DOR of pooled studies was $22(15-32)$, and the AUC for SROC was 0.89 (95\% CI 0.86-0.92), indicating a high overall accuracy of circulating miRNAs for sepsis (Table 2 and Fig. 3a, b).

In all of these studies, 4 studies analyzed the diagnostic accuracy of PCT for sepsis; the pooled Sen and Spe were 0.73 (95\% CI 0.66-0.79) and 0.86 (95\% CI 0.61-0.96), respectively. The PLR and NLR were 5.2 (95\% CI 1.616.8) and 0.31 (95\% CI $0.23-0.43)$, respectively. The DOR of pooled studies was 17 (95\% CI 4-68), and the AUC for SROC was 0.74 (95\% CI 0.70-0.77) (Table 2).

Furthermore, 4 studies analyzed the diagnostic accuracy of CRP for sepsis; the pooled Sen and Spe were 0.77 (95\% CI 0.73-0.81) and 0.71 (95\% CI 0.29-0.94), respectively. The DOR of pooled studies was 7 (95\% CI 1-48), and the AUC for SROC was 0.77 (95\% CI 0.730.81) (Table 2).

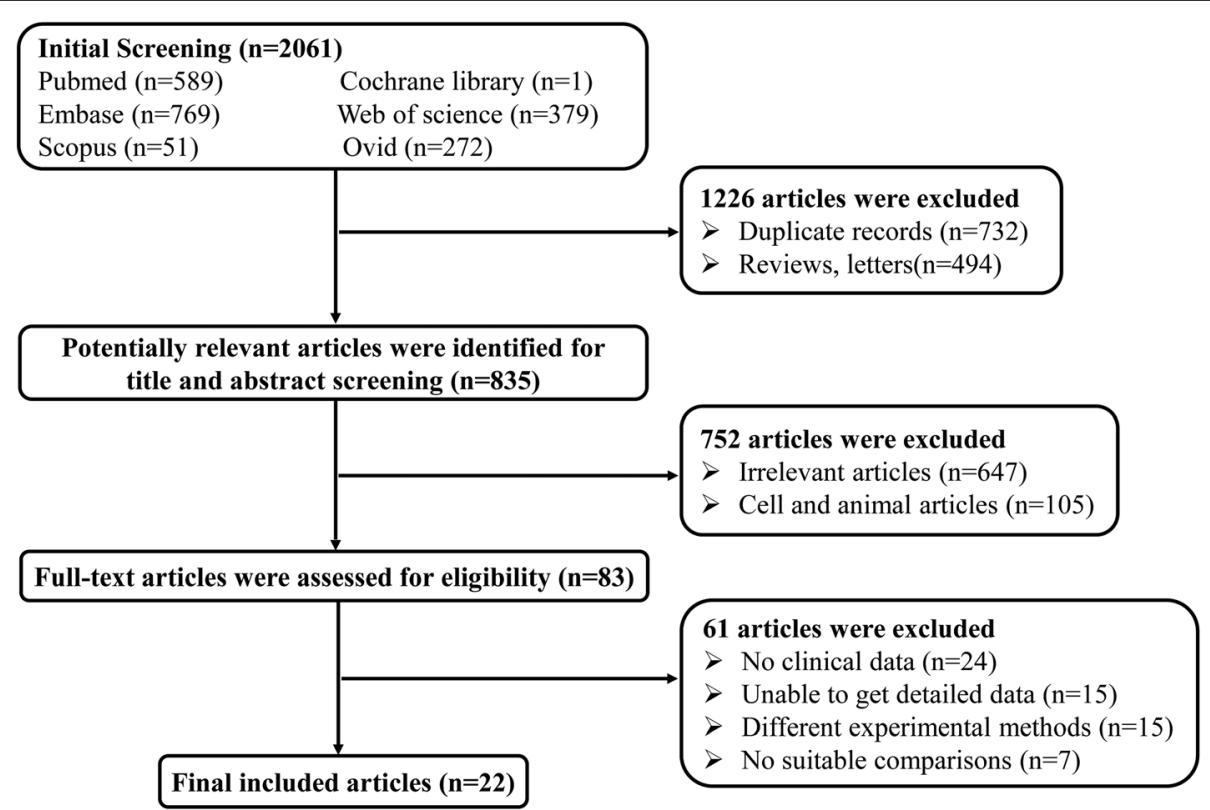

Fig. 1 Flow diagram of the study selection 


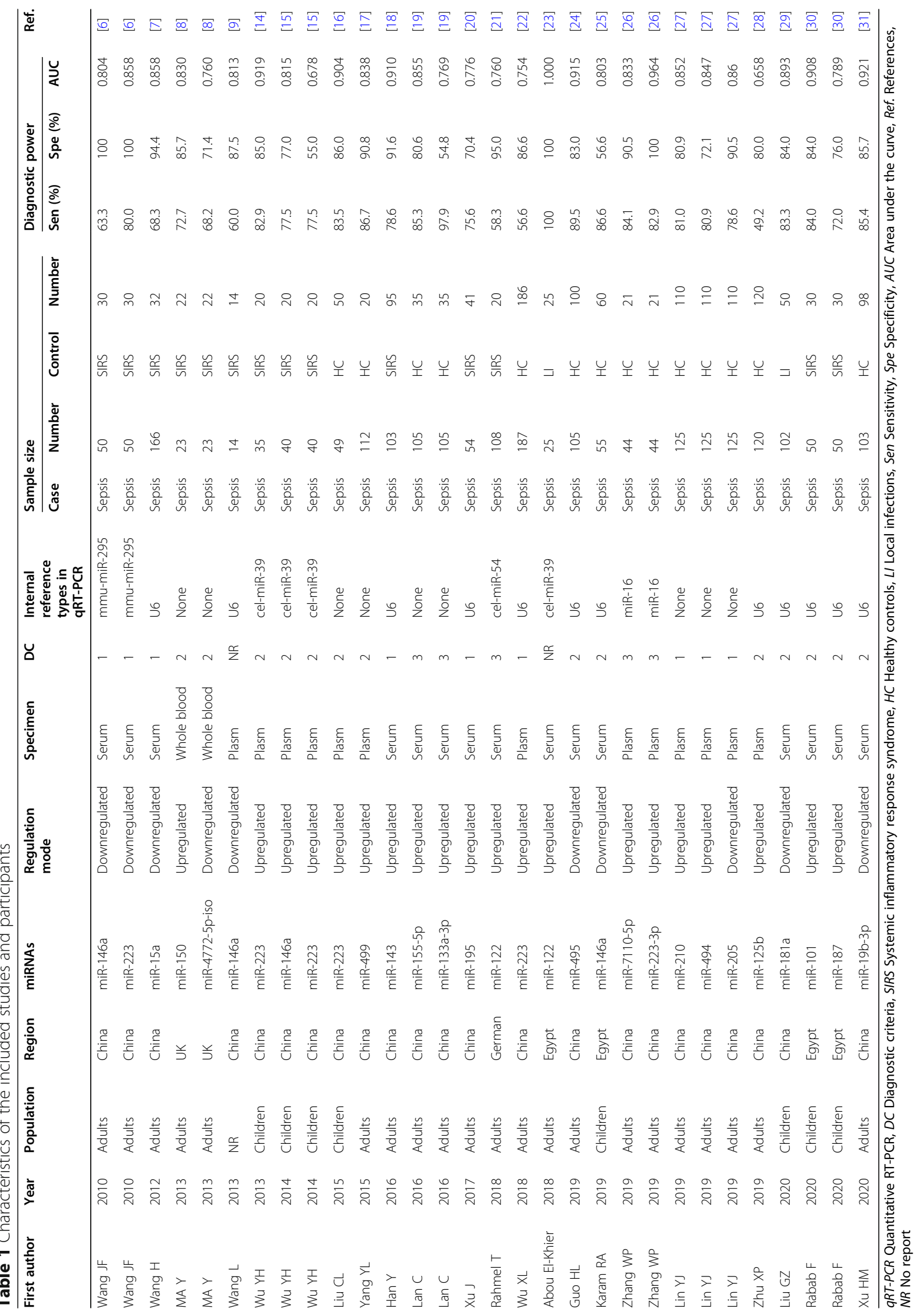




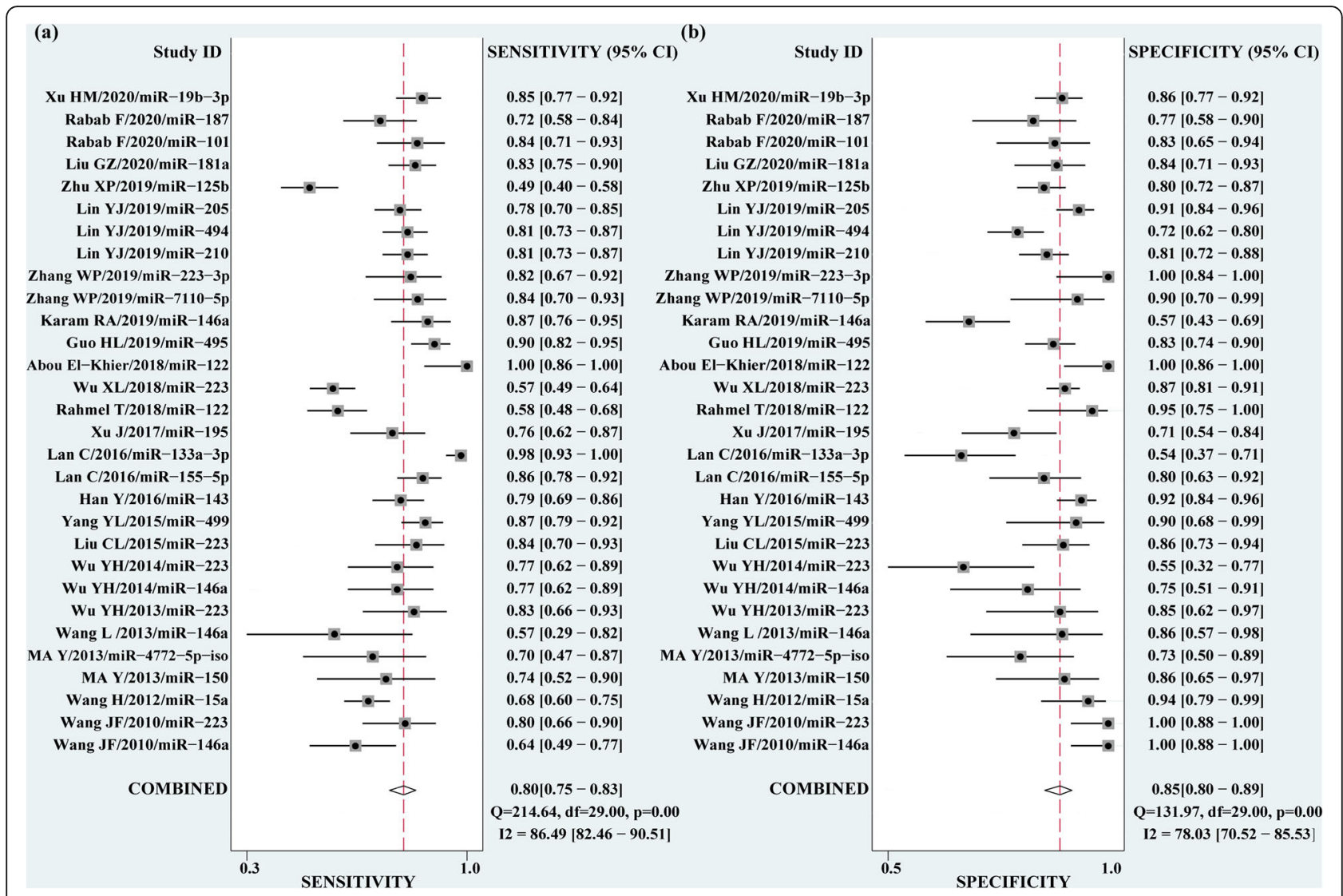

Fig. 2 Forest plots of pooled sensitivity (Sen) and specificity (Spe) of circulating miRNAs for the diagnosis of sepsis. a Sen. b Spe

The OA value of miRNAs (79.02\%) and PCT (76.95\%) were higher than CRP $(61.22 \%)(P<0.000)$. The OA value confirmed no significant difference in the diagnostic accuracy between miRNAs and PCT $(P$ $=0.373$ ) (Fig. 3c).

\section{Diagnostic accuracy of miR-223}

miR-223 was reported in 6 studies of collected researches. The pooled Sen, Spe, AUC, and DOR were 0.77 (95\% CI 0.67-0.84), 0.91 (95\% CI 0.73-0.97), 0.87
(95\% CI 0.84-0.90), and 33 (95\% CI 8-142), respectively (Table 2).

\section{Meta-regression and subgroup analysis}

The heterogeneity was explored using multiple univariable bivariate meta-regression models. The effect of each covariate on Sen was estimated separately from that on Spe (Fig. 4). The diagnostic criteria did not have an effect on miRNA Sen and Spe $(P>0.05)$, and the covariate of the population did not have an effect on Spe. In

Table 2 Diagnostic accuracy of miRNAs, PCT, and CRP for sepsis

\begin{tabular}{|c|c|c|c|c|c|c|c|c|c|}
\hline Index & $\begin{array}{l}\text { Number of } \\
\text { studies }\end{array}$ & $\begin{array}{l}\text { Number of } \\
\text { patients }\end{array}$ & $\begin{array}{l}\text { Sen } \\
(95 \% \mathrm{Cl})\end{array}$ & $\begin{array}{l}\text { Spe } \\
(95 \% \mathrm{Cl})\end{array}$ & $\begin{array}{l}\text { PLR } \\
(95 \% \mathrm{Cl})\end{array}$ & $\begin{array}{l}\text { NLR } \\
(95 \% \mathrm{Cl})\end{array}$ & $\begin{array}{l}\text { DOR } \\
(95 \% \mathrm{Cl})\end{array}$ & $\begin{array}{l}\text { AUC } \\
(95 \% \mathrm{Cl})\end{array}$ & $\begin{array}{l}O A \\
(\%)\end{array}$ \\
\hline miRNAs & 30 & 3914 & $\begin{array}{l}0.80 \\
(0.75-0.83)\end{array}$ & $\begin{array}{l}0.85 \\
(0.80-0.89)\end{array}$ & $\begin{array}{l}5.3 \\
(4.0-6.9)\end{array}$ & $\begin{array}{l}0.24 \\
(0.20-0.29)\end{array}$ & $\begin{array}{l}22 \\
(15-32)\end{array}$ & $\begin{array}{l}0.89 \\
(0.86-0.92)\end{array}$ & 79.02 \\
\hline PCT & 4 & 347 & $\begin{array}{l}0.73 \\
(0.66-0.79)\end{array}$ & $\begin{array}{l}0.86 \\
(0.61-0.96)\end{array}$ & $\begin{array}{l}5.2 \\
(1.6-16.8)\end{array}$ & $\begin{array}{l}0.31 \\
(0.23-0.43)\end{array}$ & $\begin{array}{l}17 \\
(4-68)\end{array}$ & $\begin{array}{l}0.74 \\
(0.70-0.77)\end{array}$ & 76.95 \\
\hline CPR & 4 & 245 & $\begin{array}{l}0.77 \\
(0.73-0.81)\end{array}$ & $\begin{array}{l}0.71 \\
(0.29-0.94)\end{array}$ & $\begin{array}{l}2.6 \\
(0.7-9.4)\end{array}$ & $\begin{array}{l}0.37 \\
(0.18-0.73)\end{array}$ & $\begin{array}{l}7 \\
(1-48)\end{array}$ & $\begin{array}{l}0.77 \\
(0.73-0.81)\end{array}$ & 61.22 \\
\hline miR-223 & 6 & 732 & $\begin{array}{l}0.77 \\
(0.67-0.84)\end{array}$ & $\begin{array}{l}0.91 \\
(0.73-0.97)\end{array}$ & $\begin{array}{l}8.3 \\
(2.5-27.9)\end{array}$ & $\begin{array}{l}0.25 \\
(0.17-0.38)\end{array}$ & $\begin{array}{l}33 \\
(8-142)\end{array}$ & $\begin{array}{l}0.87 \\
(0.84-0.90)\end{array}$ & 79.25 \\
\hline
\end{tabular}

miRNAs micrornas, PCT Procalcitonin, CRP C-reactive protein, 95\% Cl 95\% confidence intervals, Sen Sensitivity, Spe Specificity, PLR Positive likelihood ratios, NLR Negative likelihood ratios, DOR Diagnostic odds ratio, AUC Area under the curve, OA Overall accuracy 


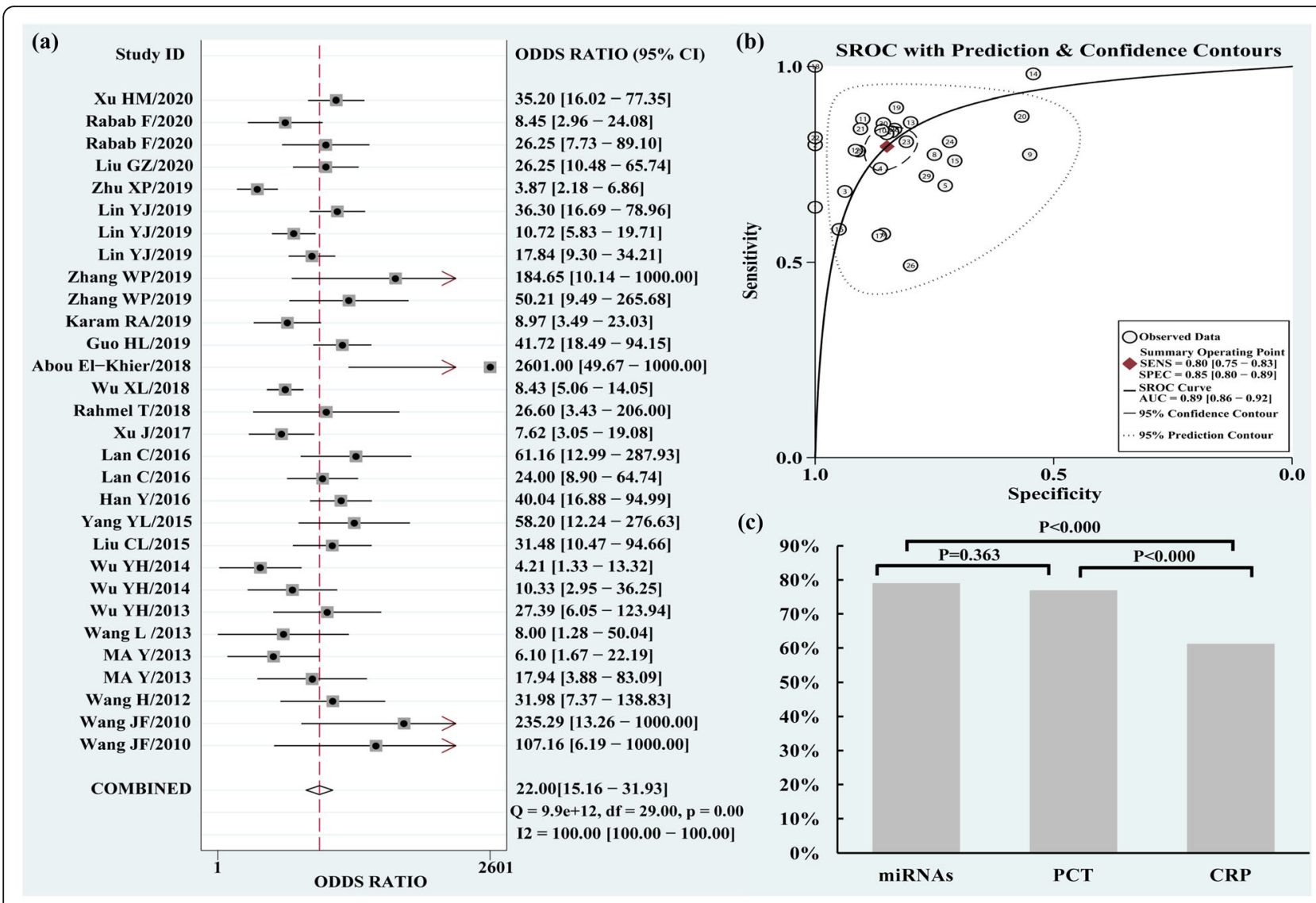

Fig. 3 Diagnostic odds ratio (DOR), summary receiver operating characteristic (SROC) curve, and overall accuracy (OA) value of circulating miRNAs for the diagnosis of sepsis. a DOR. b SROC curve. c OA value

addition, the rest of the covariates were statistically significant for Sen and Spe.

Subgroup analyses of miRNAs were further performed due to obvious heterogeneity. As shown in Table 3, among studies examining only adult patients, the Sen and Spe of circulating miRNAs were $0.80(0.73-0.85)$ and $0.88(0.82-0.92)$, respectively. The DOR of studies using serum samples was higher than that of studies using plasma samples (32 versus 17). The Sen, Spe, and DOR of miRNAs in patients with sepsis reference to Sepsis-3 were higher than those in patients reference to Sepsis-1 or Sepsis-2. Non-U6, as an internal control to normalize the expression levels of miRNAs, showed superiority compared with U6. The pooled Sen, Spe, PLR, NLR, DOR, and AUC in the non-U6 group were 0.79 (0.70-0.86), 0.96 (0.82-0.99), 19.5 (3.9-97.8), 0.22 (0.15$0.32), 89$ (15-518), and 0.90 (0.87-0.92), respectively. In the subgroup of control groups, the pooled Sen and Spe of miRNAs for sepsis were $0.74(0.69-0.78)$ and 0.87 $(0.79-0.92)$ versus SIRS and $0.83(0.76-0.88)$ and 0.82 (0.76-0.87) versus $\mathrm{HC}$, respectively.

\section{Publication bias}

A funnel graph was performed to assess the likelihood of publication bias. Deeks' test indicated no potential publication bias in all the variables analyzed in this study (Supplementary Figure 2c).

\section{Clinical utility of index test}

Fagan's nomogram was used to assess the post-test probabilities. When the pre-test probability was set at $20 \%$, the post-test probability arrived at $57 \%$ with PLR of 5 and $6 \%$ with NLR of 0.24 (Supplementary Figure 2d).

\section{Discussion}

Sepsis is a significant public health problem, with high mortality and long-term morbidity [3]. Good evidence of a mortality benefit in the early diagnosis and treatment of sepsis and septic shock [5]. However, it is not always easy to distinguish sepsis and SIRS in the early stage and is even sometimes impossible. A number of studies have investigated miRNAs as efficient biomarkers in various 


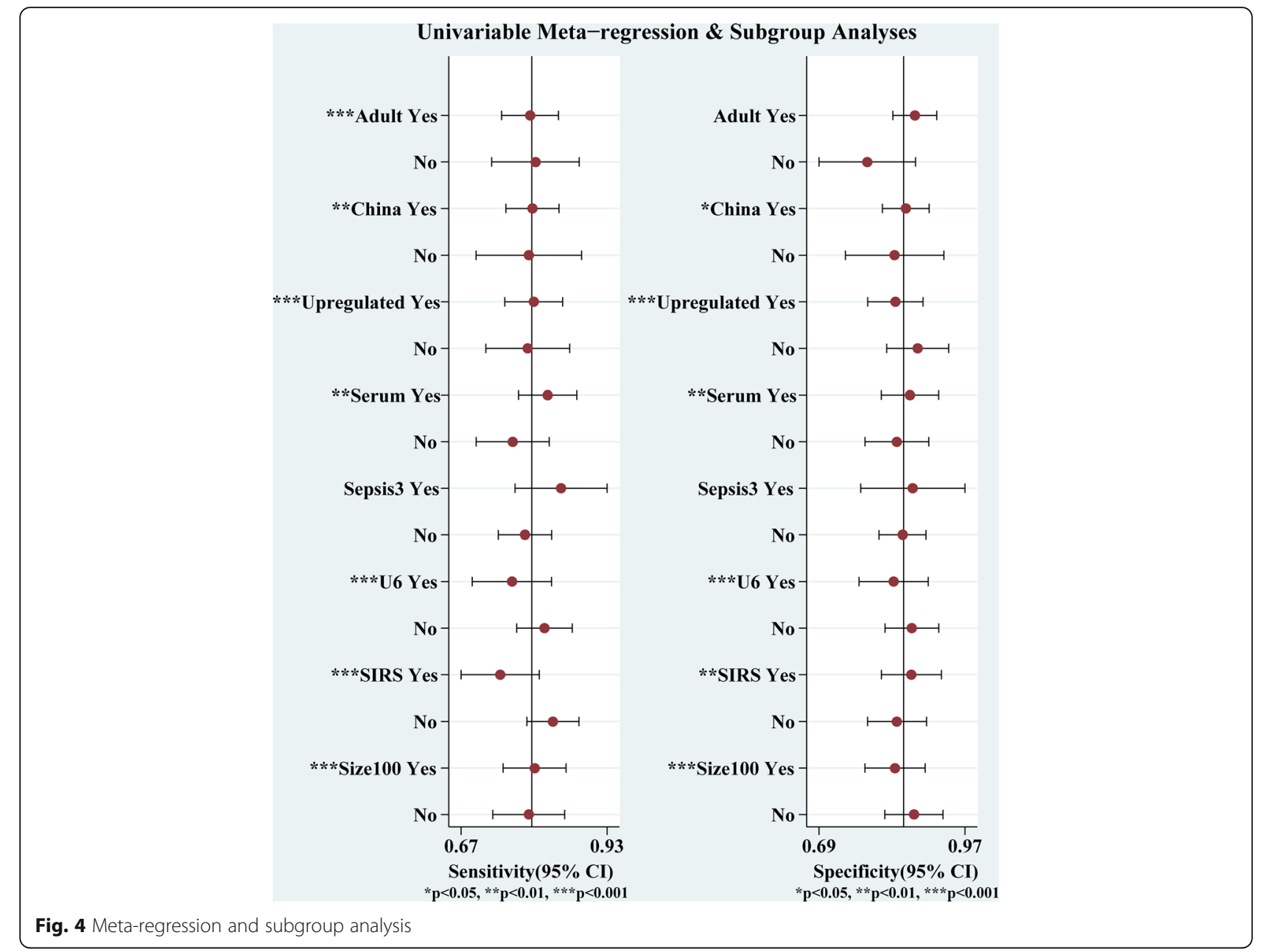

phases of sepsis [11]. Therefore, the present study comprehensively evaluated the diagnostic accuracy of circulating miRNAs in sepsis patients via a systematic review and meta-analysis.

In this study, we found the Sen, Spe, and DOR of circulating miRNAs for diagnosis of sepsis were higher than PCT and CRP. The OA value of miRNAs and PCT were significantly higher than CRP, while no significant difference was found between miRNAs and CRP. The results of the subgroup analysis showed adults and patients diagnosed by reference to Sepsis-3 had a higher value of DOR. In addition, improvement of miRNA accuracy for the detection of sepsis was observed in the subgroup of serum type, internal reference of non-U6, and downregulation of miRNA expression.

Although different screening tools and biomarkers, such as white cell count, neutrophil count, interleukin 6 (IL-6), CRP, and PCT, have been used for sepsis diagnosis, none of them is proven to be specific [5]. Previous studies demonstrated CRP lack specificity for sepsis due to an increase in non-infectious inflammatory conditions [33]. The levels of PCT could help to guide the antibiotic therapy in patients with sepsis, while the heterogeneous data of PCT failed to provide guidance for the benefits of sepsis patients [34, 35]. Current literature suggested miRNAs played a vital role in the pathophysiology of sepsis and could distinguish the various phases of sepsis [69, 11, 14-31]. Several miRNAs, such as miR-146-a, miR-125b, and miR-223, were positively or negatively associated with sepsis severity $[22,25,28]$. In this present study, the AUC of miRNAs was 0.89 (0.860.92), which is higher than that of PCT [0.74 (0.700.77)] and CRP [0.77 (0.73-0.81)]. However, the OA value showed no significant difference between miRNA and PCT. Notably, a number of miRNAs have proved to be not only as diagnostic markers (miR15a, miR-16, miR-223, miR-499-5p) but also as prognostic markers (miR-193b, miR-483-5p, and miR-574$5 p)$ for sepsis $[6-9,36]$. These results indicated circulating miRNAs could have the ability to monitor the progress of sepsis. 
Table 3 Summary diagnostic power based on subgroup analyses

\begin{tabular}{|c|c|c|c|c|c|c|c|c|c|}
\hline Subgroups & $\begin{array}{l}\text { Number of } \\
\text { studies }\end{array}$ & $\begin{array}{l}\text { Cases number } \\
\text { of sepsis }\end{array}$ & $\begin{array}{l}\text { Cases number } \\
\text { of controls }\end{array}$ & $\begin{array}{l}\text { Sen } \\
(95 \% \mathrm{Cl})\end{array}$ & $\begin{array}{l}\text { Spe } \\
(95 \% \mathrm{Cl})\end{array}$ & $\begin{array}{l}\text { PLR } \\
(95 \% \mathrm{Cl})\end{array}$ & $\begin{array}{l}\text { NLR } \\
(95 \% \mathrm{Cl})\end{array}$ & $\begin{array}{l}\text { DOR } \\
(95 \% \mathrm{Cl})\end{array}$ & $\begin{array}{l}\text { AUC } \\
(95 \% \mathrm{Cl})\end{array}$ \\
\hline \multicolumn{10}{|l|}{ Population } \\
\hline Adults & 21 & 1902 & 1283 & $\begin{array}{l}0.80 \\
(0.73-0.85)\end{array}$ & $\begin{array}{l}0.88 \\
(0.82-0.92)\end{array}$ & $\begin{array}{l}6.4 \\
(4.4-9.4)\end{array}$ & $\begin{array}{l}6.4 \\
(4.4-9.4)\end{array}$ & $\begin{array}{l}28 \\
(17-46)\end{array}$ & $\begin{array}{l}0.91 \\
(0.88-0.93)\end{array}$ \\
\hline Children & 8 & 421 & 280 & $\begin{array}{l}0.81 \\
(0.77-0.85)\end{array}$ & $\begin{array}{l}0.77 \\
(0.67-0.84)\end{array}$ & $\begin{array}{l}3.47 \\
(2.4-5.0)\end{array}$ & $\begin{array}{l}0.24 \\
(0.19-0.30)\end{array}$ & $\begin{array}{l}14 \\
(8-24)\end{array}$ & $\begin{array}{l}0.82 \\
(0.79-0.86)\end{array}$ \\
\hline \multicolumn{10}{|l|}{ Region } \\
\hline China & 23 & 2003 & 1368 & $\begin{array}{l}0.80 \\
(0.75-0.84)\end{array}$ & $\begin{array}{l}0.85 \\
(0.80-0.89)\end{array}$ & $\begin{array}{l}5.4 \\
(4.0-7.1)\end{array}$ & $\begin{array}{l}0.24 \\
(0.19-0.30)\end{array}$ & $\begin{array}{l}23 \\
(15-33)\end{array}$ & $\begin{array}{l}0.89 \\
(0.86-0.92)\end{array}$ \\
\hline Non-China & 7 & 334 & 209 & $\begin{array}{l}0.80 \\
(0.67-0.89)\end{array}$ & $\begin{array}{l}0.84 \\
(0.69-0.93)\end{array}$ & $\begin{array}{l}5.1 \\
(2.4-11.0)\end{array}$ & $\begin{array}{l}0.24 \\
(0.13-0.43)\end{array}$ & $\begin{array}{l}21 \\
(7-71)\end{array}$ & $\begin{array}{l}0.89 \\
(0.86-0.91)\end{array}$ \\
\hline \multicolumn{10}{|l|}{ Regulation mode } \\
\hline Upregulated & 20 & 1544 & 1031 & $\begin{array}{l}0.80 \\
(0.74-0.85)\end{array}$ & $\begin{array}{l}0.83 \\
(0.78-0.87)\end{array}$ & $\begin{array}{l}4.8 \\
(3.5-6.4)\end{array}$ & $\begin{array}{l}0.24 \\
(0.18-0.32)\end{array}$ & $\begin{array}{l}20 \\
(13-32)\end{array}$ & $\begin{array}{l}0.89 \\
(0.86-0.91)\end{array}$ \\
\hline Downregulated & 10 & 793 & 546 & $\begin{array}{l}0.80 \\
(0.73-0.85)\end{array}$ & $\begin{array}{l}0.89 \\
(0.80-0.94)\end{array}$ & $\begin{array}{l}7.3 \\
(4.1-13.1)\end{array}$ & $\begin{array}{l}0.23 \\
(0.18-0.29)\end{array}$ & $\begin{array}{l}32 \\
(18-56)\end{array}$ & $\begin{array}{l}0.89 \\
(0.86-0.91)\end{array}$ \\
\hline \multicolumn{10}{|l|}{ Specimen } \\
\hline Serum & 15 & 1231 & 711 & $\begin{array}{l}0.82 \\
(0.76-0.88)\end{array}$ & $\begin{array}{l}0.87 \\
(0.79-0.93)\end{array}$ & $\begin{array}{l}6.4 \\
(3.9-10.5)\end{array}$ & $\begin{array}{l}0.20 \\
(0.15-0.27)\end{array}$ & $\begin{array}{l}32 \\
(19-54)\end{array}$ & $\begin{array}{l}0.91 \\
(0.88-0.93)\end{array}$ \\
\hline Plasm & 13 & 1060 & 822 & $\begin{array}{l}0.77 \\
(0.70-0.82)\end{array}$ & $\begin{array}{l}0.84 \\
(0.78-0.88)\end{array}$ & $\begin{array}{l}4.7 \\
(3.4-6.6)\end{array}$ & $\begin{array}{l}0.28 \\
(0.21-0.37)\end{array}$ & $\begin{array}{l}17 \\
(10-29)\end{array}$ & $\begin{array}{l}0.88 \\
(0.84-0.90)\end{array}$ \\
\hline \multicolumn{10}{|l|}{ Diagnostic criteria } \\
\hline Sepsis-3 & 5 & 406 & 132 & $\begin{array}{l}0.85 \\
(0.69-0.94)\end{array}$ & $\begin{array}{l}0.87 \\
(0.69-0.95)\end{array}$ & $\begin{array}{l}6.8 \\
(2.8-16.1)\end{array}$ & $\begin{array}{l}0.17 \\
(0.08-0.35)\end{array}$ & $\begin{array}{l}40 \\
(20-81)\end{array}$ & $\begin{array}{l}0.93 \\
(0.90-0.95)\end{array}$ \\
\hline Sepsis-1/2 & 23 & 1892 & 1406 & $\begin{array}{l}0.78 \\
(0.73-0.82)\end{array}$ & $\begin{array}{l}0.84 \\
(0.79-0.88)\end{array}$ & $\begin{array}{l}4.8 \\
(3.7-6.2)\end{array}$ & $\begin{array}{l}0.26 \\
(0.22-0.32)\end{array}$ & $\begin{array}{l}18 \\
(13-26)\end{array}$ & $\begin{array}{l}0.87 \\
(0.84-0.90)\end{array}$ \\
\hline \multicolumn{10}{|c|}{ Internal reference types } \\
\hline U6 & 12 & 1109 & 856 & $\begin{array}{l}0.76 \\
(0.68-0.83)\end{array}$ & $\begin{array}{l}0.83 \\
(0.77-0.87)\end{array}$ & $\begin{array}{l}4.4 \\
(3.3-5.8)\end{array}$ & $\begin{array}{l}0.29 \\
(0.21-0.39)\end{array}$ & $\begin{array}{l}15 \\
(9-24)\end{array}$ & $\begin{array}{l}0.87 \\
(0.84-0.89)\end{array}$ \\
\hline Non-U6 & 9 & 436 & 207 & $\begin{array}{l}0.79 \\
(0.70-0.86)\end{array}$ & $\begin{array}{l}0.96 \\
(0.82-0.99)\end{array}$ & $\begin{array}{l}19.5 \\
(3.9-97.8)\end{array}$ & $\begin{array}{l}0.22 \\
(0.15-0.32)\end{array}$ & $\begin{array}{l}89 \\
(15-518)\end{array}$ & $\begin{array}{l}0.90 \\
(0.87-0.92)\end{array}$ \\
\hline \multicolumn{10}{|l|}{ Control groups } \\
\hline SIRS & 14 & 806 & 426 & $\begin{array}{l}0.74 \\
(0.69-0.78)\end{array}$ & $\begin{array}{l}0.87 \\
(0.79-0.92)\end{array}$ & $\begin{array}{l}5.7 \\
(3.5-9.4)\end{array}$ & $\begin{array}{l}0.30 \\
(0.26-0.36)\end{array}$ & $\begin{array}{l}19 \\
(11-33)\end{array}$ & $\begin{array}{l}0.82 \\
(0.78-0.85)\end{array}$ \\
\hline $\mathrm{HC}$ & 14 & 1404 & 1076 & $\begin{array}{l}0.83 \\
(0.76-0.88)\end{array}$ & $\begin{array}{l}0.82 \\
(0.76-0.87)\end{array}$ & $\begin{array}{l}4.6 \\
(3.4-6.1)\end{array}$ & $\begin{array}{l}0.21 \\
(0.15-0.30)\end{array}$ & $\begin{array}{l}22 \\
(14-35)\end{array}$ & $\begin{array}{l}0.89 \\
(0.86-0.91)\end{array}$ \\
\hline \multicolumn{10}{|l|}{ Sample size } \\
\hline$>100$ & 15 & 1746 & 1181 & $\begin{array}{l}0.81 \\
(0.73-0.87)\end{array}$ & $\begin{array}{l}0.83 \\
(0.77-0.87)\end{array}$ & $\begin{array}{l}4.7 \\
(3.6-6.2)\end{array}$ & $\begin{array}{l}0.23 \\
(0.17-0.33)\end{array}$ & $\begin{array}{l}20 \\
(13-30)\end{array}$ & $\begin{array}{l}0.89 \\
(0.86-0.91)\end{array}$ \\
\hline$<100$ & 15 & 591 & 396 & $\begin{array}{l}0.78 \\
(0.74-0.82)\end{array}$ & $\begin{array}{l}0.88 \\
(0.79-0.94)\end{array}$ & $\begin{array}{l}6.7 \\
(3.7-12.2)\end{array}$ & $\begin{array}{l}0.24 \\
(0.20-0.30)\end{array}$ & $\begin{array}{l}27 \\
(13-58)\end{array}$ & $\begin{array}{l}0.85 \\
(0.82-0.88)\end{array}$ \\
\hline
\end{tabular}

miRNAs MicroRNAs, 95\% Cl 95\% confidence intervals, Sen Sensitivity, Spe Specificity, PLR Positive likelihood ratios, NLR Negative likelihood ratios, DOR Diagnostic odds ratio, AUC Area under the curve, SIRS Systemic inflammatory response syndrome, HC Healthy controls

Despite the efficacy of miRNAs, there was obvious heterogeneity in this meta-analysis. Patients diagnosed by reference to Sepsis-3 had higher Sen, Spe, and DOR of miRNAs than that of patients reference to Sepsis-1 or Sepsis-2. As a deeper understanding of the biology of sepsis, the criteria of Sepsis-3 introduced a framework based on susceptibility, pathogen, dysregulated host response, and organ dysfunction [35]. The different specimen types could have impacted the conflicting results. Our results found the accuracy of miRNAs for sepsis diagnosis in the serum samples was higher than that in the plasma. Contrastingly, other disease studies reported the expression of miRNAs in the plasma was higher than the serum due to more proteins in the plasma [37]. The same may be true of internal reference types. However, there has been no unified standard for 
the normalization of miRNA. Thus, multicenter standardization researches need to be explored for better elucidation of miRNAs as a promising biomarker in sepsis.

Our results showed dysregulation expression of miR223 showed a superior diagnostic achievement. miR-223, as a pro-inflammatory factor, is involved in several signaling pathways that control inflammatory responses and infection reaction activation, such as negative regulation of STAT3 and IL-6 expression during sepsis [38-40]. Wu et al. [22] showed miRNA-223 expression was positively correlated with APACHE II score as well. Of note, Wang et al. [6] suggested that miR-223 in serum was downregulated among sepsis patients, while other five studies demonstrated miR-223 in the plasm was upregulated [14-16, 22, 26]. In fact, the conflicting results of miR-223 were also reported in hepatitis and hepatocellular carcinoma [39]. The possible explanations were that the expression of miR-223 was different among different sepsis stages and different experimental methods. However, the sample sizes for the evaluation of miR-233 were not large enough. Therefore, more additional researches are needed to assess the benefit of miR-233 during the course of sepsis.

Despite miRNAs as a promising diagnostic biomarker for sepsis, there are still several potential limitations. First, heterogeneity was observed in our meta-analysis. However, there was no significant threshold effect. Further subgroup analyses improved the heterogeneity. Second, miRNAs in the included patients were confirmed after sepsis diagnosis by the clinic criteria, which may add population selection bias. In addition, the included studies did not evaluate the correlation between miRNA expression and illness severity in detail. Furthermore, we could not control the statistical methods among the included studies, which may influence the results of the meta-analysis.

\section{Conclusions}

In conclusion, circulating miRNAs, especially for miR223, are potential markers for distinguishing sepsis from SIRS and HC. Better results could be obtained for adults and patients diagnosed by reference to Sepsis-3. Further large and well-designed studies should be explored to identify the role of promising miRNAs in sepsis.

\section{Supplementary Information}

Supplementary information accompanies this paper at https://doi.org/10 1186/s40560-020-00497-6.

Additional file 1: Supplementary Figure 1. A summary of methodological qualities included articles using the QUADAS-2 criteria.

Additional file 2: Supplementary Figure 2. The ROC plot, Galbraith, Deeks' funnel plot, and Fagan's Nomogram of the diagnostic meta- analysis. (a) ROC plot; (b) Galbraith; (c) Deeks' funnel plot; (d) Fagan's Nomogram.

Additional file 3: Supplemental Table 1. The research type and severity characteristics of 22 included studies

\section{Abbreviations}

miRNAs: MicroRNAs; QUADAS-2: Quality in Prognostic Studies; Sen: Sensitivity; Spe: Specificity; PLR: Positive likelihood ratios; NLR: Negative likelihood ratios; DOR: Diagnostic odds ratio; AUC: Area under the curve; OA: Overall accuracy; SROC: Summary receiver operating characteristic; $95 \%$ Cl: 95\% confidence intervals; PCT: Procalcitonin; CRP: C-reactive protein; SIRS: Systemic inflammatory response syndrome; HC: Healthy controls; IL6: Interleukin 6

\section{Acknowledgements}

Not applicable.

\section{Authors' contributions}

The work presented here was carried out in collaboration between all authors. WY and YQQ developed the concept and designed the study. XMS and WY carried out the literature research and study selection. JJZ and YCH co-worked on the associated data collection. The qualities of the included studies were carried out by XMS and WY. Disagreements were resolved by JPT and LZ. Data synthesis and analysis were carried out by WY, JPT, and ZJZ. The manuscript was written by WY and corrected by XMS and JJZ. All authors discussed the results and implications and commented on the manuscript at all stages. The authors read and approved the final manuscript.

\section{Funding}

This study was funded by the Youth Program of the National Natural Science Foundation of China (No. 81803589).

\section{Availability of data and materials}

All data generated or analyzed during this study are included in this published article and its supplementary information files.

Ethics approval and consent to participate

Not applicable.

\section{Consent for publication}

All authors have seen and approved the content and fulfill the journal's requirements for authorship.

\section{Competing interests}

The authors declare that they have no competing interests.

\section{Author details}

'State Key Laboratory for Diagnosis and Treatment of Infectious Diseases, National Clinical Research Center for Infectious Diseases, Collaborative Innovation Center for Diagnosis and Treatment of Infectious Diseases, Zhejiang Provincial Key Laboratory for Drug Clinical Research and Evaluation, The First Affiliated Hospital, Zhejiang University School of Medicine, Hangzhou, China. ${ }^{2}$ Department of Infectious Diseases, Zhejiang Provincial People's Hospital, People's Hospital of Hangzhou Medical College, Hangzhou, China.

Received: 26 July 2020 Accepted: 30 September 2020 Published online: 02 November 2020

\section{References}

1. Singer M, Deutschman CS, Seymour CW, Shankar-Hari M, Annane D, Bauer $M$, et al. The third international consensus definitions for sepsis and septic shock (Sepsis-3). JAMA. 2016;315(8):801-10. https://doi.org/10.1001/jama. 2016.0287.

2. Luhr R, Cao Y, Söderquist B, Cajander S. Trends in sepsis mortality over time in randomized sepsis trials: a systematic literature review and meta-analysis of mortality in the control arm, 2002-2016. Crit Care. 2019;23(1):241. https:// doi.org/10.1186/s13054-019-2528-0. 
3. Cecconi M, Evans L, Levy M, Rhodes A. Sepsis and septic shock. Lancet. 2018;392(10141):75-87. https://doi.org/10.1016/\$0140-6736(18)30696-2.

4. Angus DC, van der Poll T. Severe sepsis and septic shock. N Engl J Med. 2013;369(9):840-51. https://doi.org/10.1056/NEJMra1208623.

5. Del Pozo JL. Stewardship in sepsis. Rev Esp Quimioter. 2019;32 Suppl 2(Suppl 2):42-6.

6. Wang JF, Yu ML, Yu G, Bian JJ, Deng XM, Wan XJ, et al. Serum miR-146a and miR-223 as potential new biomarkers for sepsis. Biochem Biophys Res Commun. 2010;394(1):184-8. https://doi.org/10.1016/j.bbrc.2010.02.145

7. Wang HJ, Zhang PJ, Chen WJ, Feng D, Jia YH, Xie LX. Evidence for serum miR-15a and miR-16 levels as biomarkers that distinguish sepsis from systemic inflammatory response syndrome in human subjects. Clin Chem Lab Med. 2012;50(8):1423-8. https://doi.org/10.1515/cclm-2011-0826.

8. Ma Y, Vilanova D, Atalar K, Delfour O, Edgeworth J, Ostermann M, et al. Genome-wide sequencing of cellular microRNAs identifies a combinatorial expression signature diagnostic of sepsis. PLoS One. 2013;8(10):e75918. https://doi.org/10.1371/journal.pone.0075918.

9. Wang L, Wang HC, Chen C, Zeng J, Wang Q, Zheng L, et al. Differential expression of plasma miR-146a in sepsis patients compared with nonsepsis-SIRS patients. Exp Ther Med. 2013;5(4):1101-4. https://doi.org/10. 3892/etm.2013.937.

10. O'Neill LA, Sheedy FJ, McCoy CE. MicroRNAs: the fine-tuners of toll-like receptor signalling. Nat Rev Immunol. 2011;11(3):163-75. https://doi.org/10. 1038/nri2957.

11. Kingsley SMK, Bhat BV. Role of microRNAs in sepsis. Inflamm Res. 2017;66(7): 553-69. https://doi.org/10.1007/s00011-017-1031-9.

12. Moher D, Liberati A, Tetzlaff J, Altman DG, PRISMA Group. Preferred reporting items for systematic reviews and meta-analyses: the PRISMA statement. BMJ. 2009;339:b2535. https://doi.org/10.1136/bmj.b2535.

13. Whiting PF, Rutjes AW, Westwood ME, Mallett S, Deeks JJ, Reitsma JB, et al. QUADAS-2: a revised tool for the quality assessment of diagnostic accuracy studies. Ann Intern Med. 2011;155(8):529-36. https://doi.org/10.7326/00034819-155-8-201110180-00009.

14. Wu YH, Li CR, He YX, Yang YL, Wang GB, Wen PQ, et al. Expression of plasma mieroRNA-223 in pediatric sepsis patients and its clinical significance. Chin J Appl Clin Pediatr. 2013;28(18):1390-2. https://doi.org/10. 3760/cma.jissn.2095-428X.2013.18.009.

15. Wu YH, Li CR, He YX, Li Q, Wang GB, Wen PQ, et al. Relationship between expression of microRNA and inflammatory cytokines plasma level in pediatric patients with sepsis. Chin J Pediatr. 2014;52(1):28-33. https://doi. org/10.3760/cma.jissn.0578-1310.2014.01.007.

16. Liu CL, Lu LL, Liang GL, Guo YX, Dong YF. Expression of plasma microRNA 223 and HMGB-1 in pediatric sepsis patients and its clinical significance. J Clin Pediatr Dent. 2015;33(5):459-61. https://doi.org/10.3969/j.issn.1000-3606. 2015.05.015

17. Yang YL, He J, Xiao ZY. The value of microRNA-499 in the diagnosis of myocardial injury in patients with sepsis. Chin Crit Care Med. 2015;3:218-20. https://doi.org/10.3760/cma.j.issn.2095-4352.2015.03.012.

18. Han Y, Dai QC, Shen HL, Zhang XW. Diagnostic value of elevated serum miRNA-143 levels in sepsis. J Int Med Res. 2016;44(4):875-81. https://doi.org/ $10.1177 / 0300060516645003$.

19. Lan C, Shi XP, Guo NN, Pei H, Zhang HL. Value of serum miR-155-5p and miR-133a-3p expression for the diagnosis and prognosis evaluation of sepsis. Chin Crit Care Med. 2016;28(8):694-8. https://doi.org/10.3760/cma.j. issn.2095-4352.2016.08.005.

20. Xu J, Fan MY, Han XT. Serum miR-195: function as a potential diagnostic biomarker in Chinese septic patients. Int J Clin Exp Med. 2017;10(3):4756-63.

21. Rahmel T, Schäfer ST, Frey UH, Adamzik M, Peters J. Increased circulating microRNA-122 is a biomarker for discrimination and risk stratification in patients defined by Sepsis-3 criteria. PLoS One. 2018;13(5):e0197637. https:// doi.org/10.1371/journal.pone.0197637.

22. Wu X, Yang J, Yu L, Long D. Plasma miRNA-223 correlates with risk, inflammatory markers as well as prognosis in sepsis patients. Medicine (Baltimore). 2018;97(27):e11352. https://doi.org/10.1097/MD. 0000000000011352.

23. Abou El-Khier NT, Zaki ME, Alkasaby NM. Study of microRNA-122 as a diagnostic biomarker of sepsis. Egypt J Immunol. 2019;26(2):105-16.

24. Guo H, Tang L, Xu J, Lin C, Ling X, Lu C, et al. MicroRNA-495 serves as a diagnostic biomarker in patients with sepsis and regulates sepsis-induced inflammation and cardiac dysfunction. Eur J Med Res. 2019;24(1):37. https:// doi.org/10.1186/s40001-019-0396-3.
25. Karam RA, Zidan HE, Karam NA, Abdel Rahman DM, El-Seifi OS. Diagnostic and prognostic significance of serum miRNA-146-a expression in Egyptian children with sepsis in a pediatric intensive care unit. J Gene Med. 2019; 21(11):e3128. https://doi.org/10.1002/jgm.3128.

26. Zhang W, Jia J, Liu Z, Si D, Ma L, Zhang G. Circulating microRNAs as biomarkers for sepsis secondary to pneumonia diagnosed via sepsis 3.0. BMC Pulm Med. 2019;19(1):93. https://doi.org/10.1186/s12890-019-0836-4.

27. Lin Y, Ding Y, Song S, Li M, Wang T, Guo F. Expression patterns and prognostic value of miR-210, miR-494, and miR-205 in middle-aged and old patients with sepsis-induced acute kidney injury. Bosn J Basic Med Sci. 2019: 19(3):249-56. https://doi.org/10.17305/bjbms.2019.4131.

28. Zhu X. MiR-125b but not miR-125a is upregulated and exhibits a trend to correlate with enhanced disease severity, inflammation, and increased mortality in sepsis patients. J Clin Lab Anal. 2020;34(3):e23094. https://doi. org/10.1002/jcla.23094.

29. Liu G, Liu W, Guo J. Clinical significance of miR-181a in patients with neonatal sepsis and its regulatory role in the lipopolysaccharide-induced inflammatory response. Exp Ther Med. 2020;19(3):1977-83. https://doi.org/ 10.3892/etm.2020.8408.

30. Rabab FS, Ahmed AS, Heba MAEK. Evaluation of the clinical value of circulating miR-101, miR-187 and miR-21 in neonatal sepsis diagnosis and prognosis. Egyp J Med Human Genet. 2020;21:12. https://doi.org/10.1186/ s43042-020-00052-w.

31. Xu H, Liu X, Ni H. Clinical significance of miR-19b-3p in patients with sepsis and its regulatory role in the LPS-induced inflammatory response. Eur J Med Res. 2020:25(1):9. https://doi.org/10.1186/s40001-020-00408-3.

32. Dwamena B. MIDAS: Stata module for meta-analytical integration of diagnostic test accuracy studies. 2007. https:/www.researchgate.net/ publication/4922515

33. Sankar V, Webster NR. Clinical application of sepsis biomarkers. J Anesth 2013;27(2):269-83. https://doi.org/10.1007/s00540-012-1502-7.

34. Falcão Gonçalves P, Menezes Falcão L, Duque PI. Procalcitonin as biomarker of infection: implications for evaluation and treatment. Am J Ther. 2017; 24(3):e243-9. https://doi.org/10.1097/MJT.0000000000000210.

35. Nunnally ME, Patel A. Sepsis - what's new in 2019? Curr Opin Anaesthesiol. 2019;32(2):163-8. https://doi.org/10.1097/ACO.0000000000000707.

36. Huang J, Sun Z, Yan W, Zhu Y, Lin Y, Chen J, et al. Identification of microRNA as sepsis biomarker based on miRNAs regulatory network analysis. Biomed Res Int. 2014;2014:594350. https://doi.org/10.1155/2014/ 594350.

37. McDonald JS, Milosevic D, Reddi HV, Grebe SK, Algeciras-Schimnich A. Analysis of circulating microRNA: preanalytical and analytical challenges. Clin Chem. 2011;57(6):833-40. https://doi.org/10.1373/clinchem.2010.157198.

38. Wang $X$, Huang $W$, Yang $Y$, Wang $Y$, Peng $T$, Chang J, et al. Loss of duplexmiR-223 (5p and $3 p$ ) aggravates myocardial depression and mortality in polymicrobial sepsis. Biochim Biophys Acta. 2014;1842(5):701-11. https:// doi.org/10.1016/j.bbadis.2014.01.012.

39. Benz F, Roy S, Trautwein C, Roderburg C, Luedde T. Circulating microRNAs as biomarkers for sepsis. Int J Mol Sci. 2016;17(1). https://doi.org/10.3390/ ijms17010078.

40. Haneklaus M, Gerlic M, O'Neill LA, Masters SL. miR-223: infection, inflammation and cancer. J Intern Med. 2013;274(3):215-26. https://doi.org/ 10.1111/joim.12099.

\section{Publisher's Note}

Springer Nature remains neutral with regard to jurisdictional claims in published maps and institutional affiliations.

\section{Ready to submit your research? Choose BMC and benefit from:}

- fast, convenient online submission

- thorough peer review by experienced researchers in your field

- rapid publication on acceptance

- support for research data, including large and complex data types

- gold Open Access which fosters wider collaboration and increased citations

- maximum visibility for your research: over $100 \mathrm{M}$ website views per year

At $\mathrm{BMC}$, research is always in progress.

Learn more biomedcentral.com/submissions 